\title{
How clean is your toothbrush?
}

\author{
Abstracted from \\ Frazelle MR, Munro CL. \\ Toothbrush contamination: a review of the literature. Nurs Res Pract 2012; 2012: 420630. \\ Epub 2012 Jan 24. PubMed PMID: 22315679 \\ Address for correspondence: Michelle R. Frazelle, School of Nursing, Virginia Commonwealth University, \\ 1100 East Leigh Street, Richmond, VA 23298-0567, USA. E-mail: frazellemr@vcu.edu
}

\section{Question: What is the level of toothbrush contamination and does it have a role in disease transmission?}

Data sources PubMed, CINAHL, Cochrane Library, National Guidelines Clearinghouse, Web of Science and Google Scholar databases were searched.

Study selection Experimental and non-experimental English language studies in adults in hospitalised and non-hospitalised patients were included.

Data extraction and synthesis A qualitative summary of the included studies was presented.

Results Seven experimental and three descriptive studies were included. All of the studies examined toothbrush contamination and found significant bacterial retention and survival on toothbrushes after use. A number of decontamination techniques were studied and a range of active agents reduced bacterial load. Closed storage containers generally increased bacterial load or survival times. Toothbrush design was also seen to have varying impact on bacterial load.

Conclusions The selected studies found that toothbrushes of healthy and oral diseased adults become contaminated with pathogenic bacteria from dental plaque, design, environment or a combination of factors. There are no studies that specifically examine toothbrush contamination and the role of environmental factors, toothbrush contamination, and vulnerable populations in the hospital setting (eg critically ill adults) and toothbrush use in nursing clinical practice.

\section{Commentary}

The average mouth is teeming with bacteria so it is not surprising that toothbrushes become contaminated with bacteria. The question is, is this contamination of significance? The authors of this review have addressed this question from the nursing perspective looking to assess whether there is a risk of disease transmission in the hospital and community setting. Recently there has been significant interest in the role of oral hygiene in the prevention of ventilator-associated pneumonia (VAP). For example a basic search using the terms 'oral hygiene' and 'ventilator associated pneumonia' on Medline had 89 hits, mainly from the nursing literature, including a number of reviews. ${ }^{1,2}$ Therefore this interest in the humble toothbrush is perhaps not surprising. What is surprising is the limited number of studies that were identified from what was a broad search of a number of databases.

The largest included study examined 103 toothbrushes, the smallest three, and the findings were discussed qualitatively owing to the heterogeneity of the available studies.

The recent interest in the importance of good oral hygiene in relation to VAP, and the focus of attention on hospital acquired infections highlights the importance of clear recommendations both regarding appropriate oral care for hospitalised patents of any age, particularly in view of recent systematic review highlighting the negative impact of hospitalisation on oral health, ${ }^{3}$ and the storage of toothbrushes in hospital environments. While storage issues for toothbrushes of healthy adults in the community may not be a particular concern, perhaps consideration should be given to the needs of the frailer members of the community. However while this review does give some indication of a potential risk this is a long way short of an actual risk and more research is necessary to elicit this.

Derek Richards

Centre for Evidence-based Dentistry, Oxford, UK.

1. Zamora Zamora F. [Effectiveness of oral care in the prevention of ventilatorassociated pneumonia. systematic review and meta-analysis of randomised clinical trials]. Enferm Clin. 2011; 21: 308-319. Epub 2011 Nov 25. Review. Spanish. PubMed PMID: 22118800.

2. Roberts N, Moule P. Chlorhexidine and tooth-brushing as prevention strategies in reducing ventilator-associated pneumonia rates. Nurs Crit Care. 2011; 16: 295-302. doi: 10.1111/j.1478-5153.2011.00465.x. Epub 2011 Jul 26. Review. PubMed PMID: 21999420.

3. Terezakis E, Needleman I, Kumar N, Moles D, Agudo E. The impact of hospitalization on oral health: a systematic review. J Clin Periodontol 2011; 38: 628-636. 